\title{
Medical repatriation of migrant farm workers in Ontario: a descriptive analysis
}

\author{
Aaron M. Orkin MD MSc, Morgan Lay BSocSc, Janet McLaughlin PhD, Michael Schwandt MD MPH, \\ Donald Cole MD MSc
}

Abstract

Background: Approximately 40000 migrant farm workers are employed annually in Canada through temporary foreign worker programs. Workers experiencing health conditions that prevent ongoing work are normally repatriated to their home country, which raises concerns about human rights and health equity. In this study, we present data on the reasons for medical repatriation of migrant farm workers in Ontario.

Methods: In this retrospective descriptive study, we examined medical repatriation data from Foreign Agricultural Resource Management Services, a non-profit corporation managing the contracts of more than 15000 migrant farm workers in Ontario annually. We extracted repatriation and demographic data for workers from 2001-2011. Physician volunteers used a validated system to code the reported reasons for medical repatriation. We conducted descriptive analyses of the dominant reasons for repatriation and rates of repatriation.

Results: During 2001-2011, 787 repatriations occurred among 170315 migrant farm workers arriving in Ontario (4.62 repatriations per 1000 workers). More than two-thirds of repatriated workers were aged 30-49 years. Migrant farm workers were most frequently repatriated for medical or surgical reasons (41.3\%) and external injuries including poisoning (25.5\%).

Interpretation: This study provides quantitative health data related to a unique and vulnerable occupational group. Our findings reinforce existing knowledge regarding occupational hazards and health conditions among migrant farm workers. Medical repatriation of migrant farm workers merits further examination as a global health equity concern.

$\mathrm{E}$ ach year, nearly 40000 temporary foreign worker positions are approved for employment in Canadian agriculture. ${ }^{1}$ These migrant farm workers are employed through various streams of the Temporary Foreign Worker Program, primarily the Seasonal Agricultural Worker Program. Through this program, workers from Mexico and the Caribbean are employed for up to 8 months each year, with workers often returning for multiple successive seasons. The health status of migrant farm workers and their access to health services in Canada has come under recurrent scrutiny, recently in relation to the 2013 Peart v. Ontario (Community Safety \& Correctional Services) Human Rights Tribunal of Ontario hearing into the 2002 workplace death of Jamaican farm worker, Ned Peart.

Most workers hired under the Seasonal Agricultural Worker Program undergo medical examinations before their arrival in Canada; these generally include a physical examination, blood and urine tests and chest radiography. Once in Canada, they have access to provincial health coverage, although multiple practical barriers often inhibit this access. Few studies exist regarding the occupational health of migrant farm workers in Canada. Inconsistent reporting requirements, as well as their short-term employment and residence, may contribute to incomplete reporting of the frequency, severity and nature of occupational illness among these workers. Further, their occupational health conditions may not be accurately captured in workers' compensation data or occupational surveillance systems such as the Canadian Agricultural Injury Surveillance Program.,3

Competing interests: Donald Cole is a physician with the Occupational Health Clinics for Ontario Workers (Migrant Farm Worker Project). No other competing interests declared.

This article has been peer reviewed.

Correspondence to: Aaron Orkin, aaron.orkin@mail.utoronto.ca CMAJ Open 2013.DOI:10.9778/cmajo.20140014 
When faced with health problems or injuries that prevent them from continuing work, migrant farm workers in Canada under the Seasonal Agricultural Worker Program are normally repatriated to their country of origin. Under the program's international agreements, "the employer, after consultation with the [worker's] government agent, shall be entitled for non-compliance, refusal to work, or any other sufficient reason, to terminate the worker's employment... and so cause the worker to be repatriated." "The repatriation of migrant farm workers for health-related reasons and medical termination of their employment represents a unique form of deportation from Canada. Although farm workers are entitled to receive health care before the termination of their employment and repatriation, in practice, workers are sometimes repatriated immediately, without receiving such care. ${ }^{5}$

Although the labour policy and human rights dimensions of medical repatriations and other features of Canada's temporary foreign worker program have been examined elsewhere, ${ }^{6,7}$ the illnesses and injuries leading to medical repatriation of migrant farm workers have not previously been described in the epidemiologic or occupational health literature. The primary objective of this study was to present data describing the reasons and dominant diagnostic categories for medical repatriation of migrant farm workers in Ontario between 2001 and 2011. Secondary objectives were to compute rates of dominant medical and traumatic conditions resulting in medical repatriation in this population and to explore the use of Foreign Agricultural Resource Management Services repatriation data as a source for occupational epidemiology research in this population.

\section{Methods}

\section{Data sources}

In Ontario, more than 15000 annual Seasonal Agricultural Worker Program contracts are administered by Foreign Agricultural Resource Management Services, a federally incorporated, non-profit corporation authorized by Employment and Social Development Canada, formerly Human Resources and Skills Development Canada.

Foreign Agricultural Resource Management Services maintains administrative records of the reasons for repatriation of migrant farm workers. We examined the records related to repatriation for medical purposes for 2001-2011. These data were publicly available because they were entered into evidence during the Human Rights Tribunal of Ontario hearing concerning the death of Ned Peart. ${ }^{8}$ The product of our request under the Ontario Freedom of Information and Protection of Privacy Act is included as Appendix 1 (www .cmajopen.ca/content/2/3/E192/supp1/DC1). Names of repatriated workers were redacted from the public record. All available variables were manually transcribed into an Excel database (Microsoft, Redmond, Wash.). These included worker contract year, date of birth, country of origin, date of repatriation and reason for medical repatriation. The reason for medical repatriation was captured as a 200-character freetext field in the raw data.
The number of arrivals of migrant farm workers in Ontario per year was obtained from Foreign Agricultural Resource Management Services through a data request to Human Resources and Skills Development Canada.

\section{Coding of reasons for repatriation}

A custom-built, web-based coding tool was developed to map the free text "reason for medical repatriation" field to standardized diagnostic categories, using the Google Drive forms feature (Google Inc., Mountain View, Calif.). The initial coding system was developed by 2 physician investigators (A.O. and D.C.) and was refined and validated through a series of coding tests, focus group consultation and inter-rater reliability analyses.

Ten physician volunteers with independent medical licensure in Canada were recruited to participate in a focus group for the development of a validated coding system, to classify the "reason for medical repatriation" and to act as coders. A donation to an international humanitarian charity was offered as an incentive to coders. Physician volunteers included 3 study investigators (A.O., M.S. and D.C.).

Coders received written training on the initial prototypal coding procedure and were provided with identical sets of 15 random observations for independent coding. The prototypal coding structure was evaluated for inter-rater reliability and found to have a Fleiss exact $\kappa$ value of 0.59 , showing moderate agreement between coders. ${ }^{9}$ Based on feedback from the coders, the coding system was refined by the investigators. Coders were given revised training, and all physician volunteers coded a second identical set of 16 random observations. The Fleiss exact $\kappa$ value for this final coding system was 0.62 , showing substantial inter-rater agreement. ${ }^{9}$

Each coder was provided with a random subset of 78-80 observations for coding, resulting in the classification of all medical repatriations in the data set. Each observation was categorized by the volunteer physician coders into 1 of 7 mutually exclusive groups mapped to categories of the International Statistical Classification of Diseases and Related Health Problems, 10th revision (World Health Organization, 1992): medical/surgical injuries, external injuries (trauma, including poisoning), psychiatric conditions, pre-existing musculoskeletal conditions, other identifiable injuries, explicit requests for repatriation and unintelligible or no medical condition provided. Reasons for repatriation were further classified based on body region in the case of trauma; type of medical or surgical injury; and whether the reason for repatriation was a back injury, an environmental injury, or included an explicit request for repatriation. In the event of uncertainty, coders could "request a consult," whereby the observation was re-examined and recoded through a consensus procedure by a consultation team composed of 2 investigators (A.O. and M.S.).

\section{Statistical analysis}

Univariable analysis including frequency tables and bar graphs was completed for each variable. Repatriation rates and proportions were calculated using the number and country of origin of workers entering Ontario each year as denominators. 


\section{OPEN}

Research

All statistical procedures were completed using RStudio (v. 0.97.316) open-source software.

\section{Results}

A total of 787 health repatriations occurred from 2001 to 2011. The average age of repatriated workers was 38.14 years (standard deviation 8.69 years) and more than two-thirds of repatriated workers were aged 30-49 years (Table 1). Nearly half $(48.3 \%, n=380)$ of repatriated workers returned to their home country of Mexico, and approximately a third (34.6\%, $n=272$ ) returned to Jamaica.

Over the 11 years of study, 787 of the 170315 workers who arrived in Ontario were repatriated for health-related reasons; 4.62 (95\% confidence interval [CI] 4.30-4.94) medical repatriations occurred for every 1000 workers arriving (Figure 1). As the annual number of temporary migrant workers arriving in Ontario remained stable between 2001 and 2011, the rate of injuries is close to the crude number of repatriations. The highest rate of medical repatriation occurred in 2003 when 7.81 (95\% CI 6.41-9.21) repatriations occurred for every 1000 workers. Rates of repatriation generally decreased between 2003 and 2011, except in 2008 and 2009, when rates were 4.33 (95\% CI 3.30-5.35) and 3.69 (95\% CI 2.73-4.66) repatriations per 1000 arrivals, respectively. The lowest reported rate of medical repatriations occurred in 2011, at 2.22 per 1000 workers (95\% CI 1.49-2.96).

We also examined the cumulative rate of medical repatriations based on workers' country of origin (Figure 2). Over the study period, the highest rate occurred among workers from Barbados: 9.62 (95\% CI 6.25-13.00) medical repatriations for every 1000 arrivals. The lowest rate occurred among Mexican workers: 4.38 medical repatriations per 1000 workers $(95 \%$ CI 3.94-4.82).

The frequency of medical repatriation by each of the 7 diagnostic categories is displayed in Figure 3. Migrant farm workers were most frequently repatriated for medical or surgical reasons $(41.3 \%, n=325)$, for external injuries including poisoning $(25.5 \%, n=201)$ and for other identifiable reasons $(17.3 \%, n=136)$.

Cases coded in the category of "Other identifiable" were most often cases where the reason for repatriation indicated illhealth, but was too vague to categorize. Examples include comments such as "worker is ill," "worker has medical issue," or simply "injured." Seventy-two (9.1\%) repatriations were coded as "Unintelligible/no medical condition asserted." For 7 cases, no reason for repatriation was provided; in other cases, problems with family at home or "disagreement with management" were given as the reason for repatriation. Psychiatric cases represented $3.2 \%(n=25)$ of repatriations and included reports of depression, anxiety, stress and, more generally, "mental illness." Of the $15(1.9 \%)$ repatriations arising from pre-existing musculoskeletal injuries, 7 were back-related and the remainder pertained to various pre-existing upper and lower extremity conditions. Only 13 (1.7\%) of medical repatriations resulted from migrant farm workers' requests.

More than one-quarter $(27.7 \%, n=90)$ of the 325 medical/ surgical repatriations resulted from musculoskeletal symptoms that were not identified as traumatic injuries, including back problems and both upper and lower limb conditions. A further quarter of medical/surgical repatriations $(26.5 \%, n=86)$ concerned digestive and gastroenterological issues, such as

Table 1: Sociodemographic characteristics of 787 migrant farm workers repatriated for health-related reasons, Ontario, 2001-2011

\begin{tabular}{|c|c|c|c|c|c|c|c|c|c|c|c|c|}
\hline \multirow[b]{2}{*}{ Characteristic } & \multicolumn{11}{|c|}{ No. workers (\%) } & \multirow{2}{*}{$\begin{array}{c}\text { Total, no } \\
\quad \%) \\
n=787\end{array}$} \\
\hline & $\begin{array}{c}2001 \\
n=74\end{array}$ & $\begin{array}{c}2002 \\
n=112\end{array}$ & $\begin{array}{c}2003 \\
n=119\end{array}$ & $\begin{array}{c}2004 \\
n=90\end{array}$ & $\begin{array}{c}2005 \\
n=77\end{array}$ & $\begin{array}{c}2006 \\
n=67\end{array}$ & $\begin{array}{c}2007 \\
n=51\end{array}$ & $\begin{array}{c}2008 \\
n=68\end{array}$ & $\begin{array}{c}2009 \\
n=56\end{array}$ & $\begin{array}{c}2010 \\
n=38\end{array}$ & $\begin{array}{c}2011 \\
n=35\end{array}$ & \\
\hline \multicolumn{13}{|l|}{ Age, $\mathrm{yr}^{*}$} \\
\hline 20-29 & $8(10.8)$ & $17(15.2)$ & $24(20.2)$ & $18(20.0)$ & 19 (24.7) & 12 (17.9) & $7(13.7)$ & 10 (14.7) & $8(14.3)$ & $5(13.2)$ & $6(17.1)$ & $134(17.0)$ \\
\hline $30-39$ & $21(28.4)$ & 49 (43.8) & $43(36.1)$ & $31(34.4)$ & $31(40.3)$ & $30(44.8)$ & $26(51.0)$ & 27 (39.7) & 24 (42.9) & $14(36.8)$ & 15 (42.9) & 311 (39.5) \\
\hline $40-49$ & $21(28.4)$ & $27(24.1)$ & $40(33.6)$ & $29(32.2)$ & 19 (24.7) & 19 (28.3) & $16(31.4)$ & $22(32.4)$ & 19 (33.9) & 10 (26.3) & $10(28.6)$ & 232 \\
\hline$\geq 50$ & $7 \quad(9.5)$ & $11(9.8)$ & $11 \quad(9.2)$ & $12(13.3)$ & $8(10.4)$ & $6 \quad(8.9)$ & 2 (3.9) & $9(13.2)$ & $5 \quad(8.9)$ & $9(23.7)$ & $4(11.4)$ & $82(10.4)$ \\
\hline \multicolumn{13}{|l|}{$\begin{array}{l}\text { Country of } \\
\text { origin }\end{array}$} \\
\hline Barbados & $7 \quad(9.5)$ & $8 \quad(7.1)$ & $5 \quad(4.2)$ & $7 \quad(7.8)$ & 3 (3.9) & 0 & 0 & 0 & 0 & 0 & 1 (2.9) & 31 (3.9) \\
\hline $\begin{array}{l}\text { Eastern } \\
\text { Caribbean† }\end{array}$ & $3(4.1)$ & $3(2.7)$ & 0 & 1 (1.1) & $4 \quad(5.2)$ & $2(3.0)$ & $2(3.9)$ & $2(2.9)$ & $4 \quad(7.1)$ & $4(10.5)$ & $2(5.7)$ & $27 \quad(3.4)$ \\
\hline Jamaica & $27(36.5)$ & $28(25.0)$ & $43(36.1)$ & $30(33.3)$ & $30(39.0)$ & $23(34.3)$ & $14(27.5)$ & 26 (38.2) & 22 (39.3) & $16(42.1)$ & $13(37.1)$ & 272 (34.6) \\
\hline Mexico & $24(32.4)$ & $61(54.5)$ & $62(52.1)$ & $47(52.2)$ & 32 (41.6) & $35(52.2)$ & $33(64.7)$ & 36 (52.9) & $24(42.9)$ & 15 (39.4) & $11(31.4)$ & $380(48.3)$ \\
\hline $\begin{array}{l}\text { Trinidad } \\
\text { and Tobago }\end{array}$ & $13(17.6)$ & $12(10.7)$ & $9 \quad(7.6)$ & $5 \quad(5.6)$ & $8(10.4)$ & $7(10.4)$ & $2(3.9)$ & $4 \quad(5.9)$ & $6(10.7)$ & $3 \quad(7.9)$ & 8 (22.9) & $77 \quad(9.8)$ \\
\hline
\end{tabular}


stomach pain, hernia operation or appendicitis. Among the 18 cases coded as cardiovascular, circulatory or vascularrelated, 3 were reported as "heart attack[s]." Another 3 medical repatriations were attributed to pregnancy.

Of the 201 repatriations coded as external injuries, 59 (29.3\%) occurred in upper extremities. These injuries included muscle strains; injured, broken or severed fingers, hands, wrists and shoulders; as well as 1 partial amputation. The second largest category $(n=45,22.3 \%)$ of external injuries resulting in repatriation were lower extremity injuries, such as sore or broken feet, ankles or legs, as well as torn ligaments and groin strains. Among the 35 (17.4\%) external

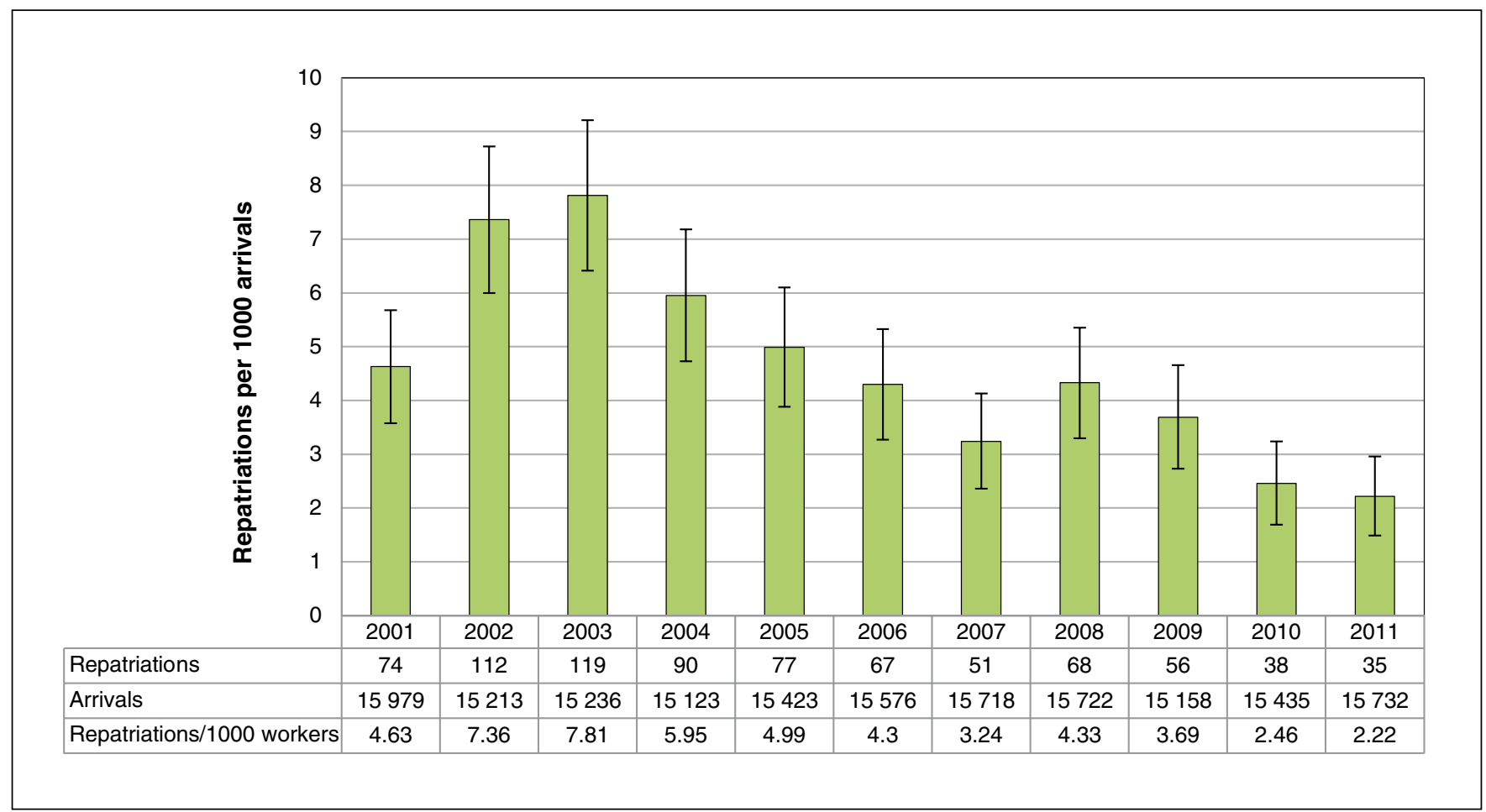

Figure 1: Annual rate of medical repatriation of migrant farm workers in Ontario, 2001-2011 $(n=787)$.

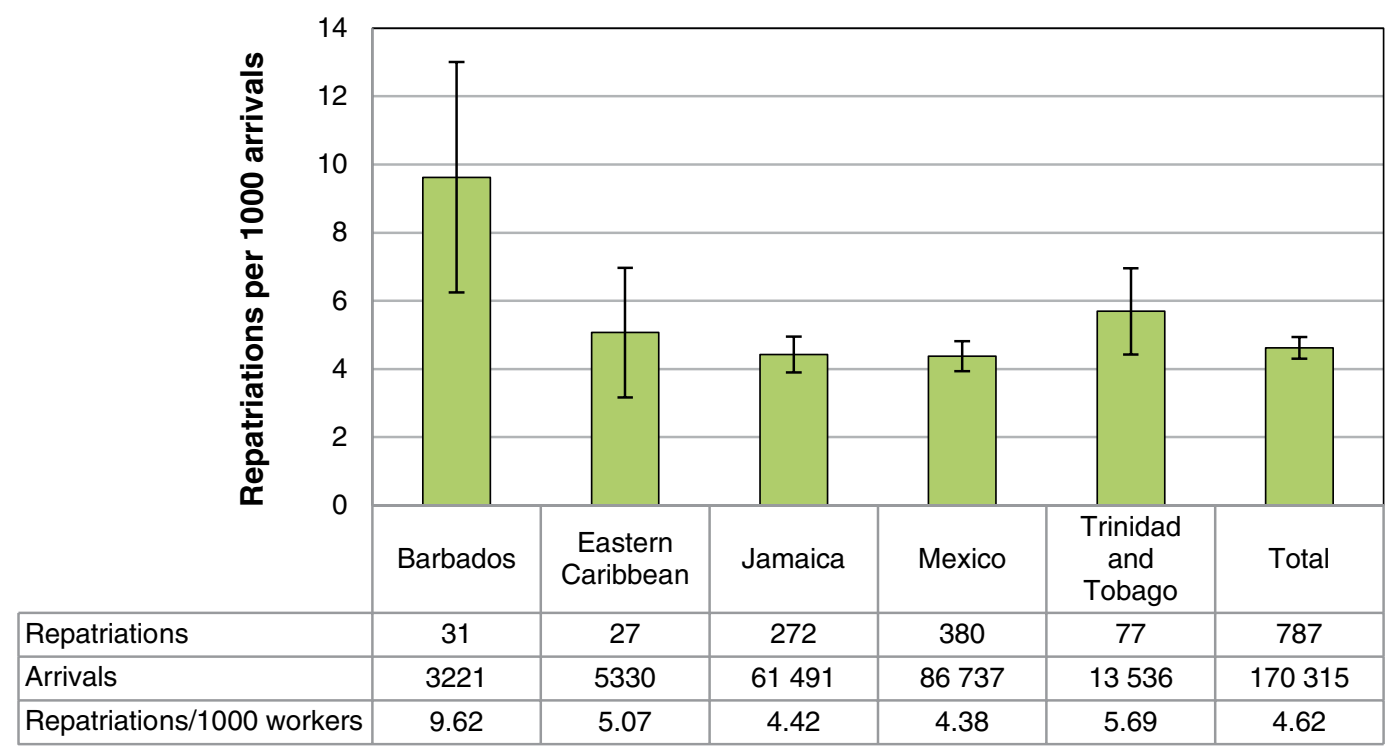

Figure 2: Rate of medical repatriation of migrant farm workers in Ontario, 2001-2011, by country of origin $(n=787)$. 
injuries identified as "Other" were 6 cases of tobacco poisoning and 4 injuries related to motor vehicle collisions.

\section{Interpretation}

A total of 787 medical repatriations occurred between 2001 and 2011. Most repatriated workers were aged 30-49 years. The highest rate of repatriations occurred in 2002 and 2003, and among workers from Barbados. During the study period, workers were most frequently repatriated for medical and surgical reasons, including musculoskeletal and gastrointestinal-related symptoms, and for external trauma, including poisoning.

The observed variations in rates of medical repatriation by country of origin may arise from the independent worker agreements between Canada and each of the providing nations. Workers from each country also work in similar but distinct agricultural contexts, with varied health risks, work conditions, and access to health services and other resources. Consular officials from the workers' various countries of origin may have different manners of intervening or advocating in medical repatriation cases.

This study adds a new dimension to the understanding of and available data sources for the health of migrant farm workers. Its central strength is the use of a previously inaccessible set of employment data and a validated coding procedure to describe medical repatriation among migrant farm workers.
Medical repatriation has not previously been described in the Canadian medical or occupational health literature. Medical repatriation is at once an occupational health event, an international deportation and a termination of employment. There are perhaps no other Canadian occupational settings where workplace injuries and illnesses, such as those described in this data set, result in employment termination and deportation without further medical care or income security. The Canadian Labour Congress has identified repatriation provisions in Seasonal Agricultural Workers Program contracts as the employer's "bluntest tool to suppress workers' rights."”

\section{Comparison with other studies}

Our study reinforces existing literature from Canada and the United States regarding the range of health conditions associated with occupational hazards among migrant farm workers, including injury; musculoskeletal, respiratory, infectious, and dermatological disease; mood disorders; and environmental illnesses. ${ }^{10-13}$ Toxic exposures, lack of occupational health regulation and enforcement, frequent use and poor maintenance of hazardous equipment, poor housing conditions, increased occupational risk taking and chronic stress have been identified in this population. ${ }^{14-18}$ Our data align with existing studies of the health of migrant farm workers by showing that injuries, musculoskeletal and gastrointestinal problems account for the majority of illnesses in this population. Ontario data over

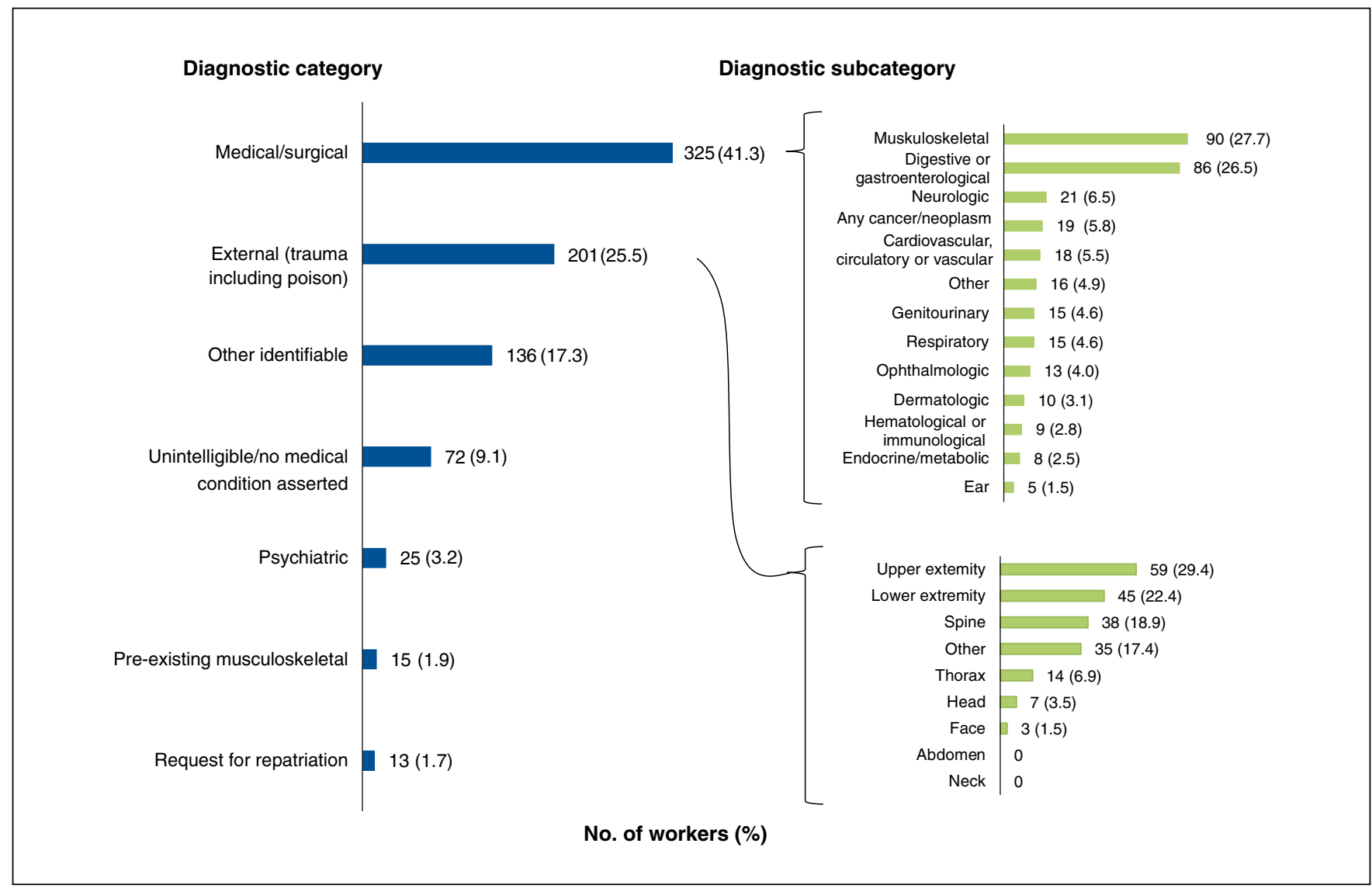

Figure 3: Diagnostic reasons for medical repatriation of migrant farm workers in Ontario, 2001-2011 $(n=787)$. 
a 3-year period $(n=888)$ showed that the top reasons migrant farm workers present to an emergency department near their workplaces include injury, gastrointestinal, musculoskeletal, respiratory, dermatologic, urinary and ophthalmologic conditions. ${ }^{19}$

Our study extends the existing literature by identifying the health conditions cited as the reason for a termination of employment and health-related repatriation. Migrant farm workers in Canada face multiple barriers to accessing health care including workers' reluctance to seek this assistance; lack of independent transportation; language and cultural differences; lack of knowledge about the health care system; long work hours and limited clinic hours; and repatriation following illnesses or injuries. ${ }^{13}$ Fear of employers or not wanting to lose paid work hours, as well as inadequate knowledge about how to make a workers' compensation claim, have also been cited as common factors impeding access to care. ${ }^{6}$

\section{Limitations}

The medical causes of repatriation and associated rates presented in this paper are difficult to compare with other occupational health phenomena because repatriation is not a feature of other Canadian occupational settings. Our study should be interpreted strictly as a description of medical repatriation. It does not capture workplace injuries or health conditions that do not result in repatriation. Thus, the reported repatriation rates underestimate the general rate of the health problems among these workers. Many migrant farm workers develop health concerns, but complete their contracts without being fired or repatriated. The reported rates also likely underestimate overall rates of migrant farm worker injury or ill health in migrant farm workers; some workers with serious illnesses or injuries may leave their workplaces but remain in Canada because they fear they will be unable to access medical care in their home countries. These workers are not identified in the Foreign Agricultural Resource Management Services repatriations data, although they may be identified in other records as being absent without leave, in breach of contract or having undergone a change of visa status. ${ }^{5}$

Without additional and separate information on workplace deaths, conclusions cannot be drawn from the Foreign Agricultural Resource Management Services repatriation data regarding work-related fatalities, either in Canada or following illnesses or injuries resulting in repatriation.

Other researchers have shown that approximately $97 \%$ of migrant farm workers in Canada are men and that sex and gender play a pivotal role in the implementation of foreign worker programs and the power relationships between workers, and between workers and their employers. ${ }^{20}$ Our redacted data set did not include the sex of workers, nor does it appear that the Foreign Agricultural Resource Management Services database captured this information. Although some conditions, such as pregnancy, reveal the sex of the worker, most do not. Thus, sex-related conclusions cannot be drawn and this represents a study limitation.

The data used in this study do not show whether illnesses and injuries in migrant farm workers resulting in repatriation are directly related to work or occurred while the worker was performing specific agricultural activities. However, most reported injuries are likely directly related to agricultural work, and migrant farm workers are considered to be in the workplace even when at their place of residence in Canada or in transit between their farming activities and residence. The data also did not show whether repatriated workers were firsttime or return employees in Canada and do not permit us to draw conclusions regarding the reasons behind the observed variations in annual repatriation rates.

The nature of the data source, as an administrative and employment database rather than an epidemiologic data source, health record or surveillance tool, limits interpretation of this study. Maintained primarily for employers, the data may not offer a reliable depiction of reasons for medical repatriation. Because Foreign Agricultural Resource Management Services is a private, employer-funded and operated organization, the data it collects are not subject to external assessment or oversight, nor to Canada's Access to Information Act. We were able to obtain repatriation data only because they were entered into evidence in a public Ontario Human Rights Tribunal hearing. Many additional variables about migrant farm workers may be maintained in other Foreign Agricultural Resource Management Services databases, but these are not available for public or academic examination or linkage with other records. Canada does not monitor or maintain records regarding the medical repatriation of migrant workers.

This data set, albeit limited and imperfect, is therefore the only source of its kind, and this study's reliable coding procedure generated high-quality data illustrating a largely unexamined phenomenon. More formal and accessible occupational epidemiologic and surveillance systems are needed for this population. Our coding and analysis procedure demonstrates that employment and administrative records might provide a useful source of occupational epidemiologic data for this population.

\section{Conclusion and future directions}

This study offers new epidemiologic and occupational health insights into the medical repatriation of workers employed in Ontario under the Seasonal Agricultural Workers Program. From 2001 to 2011, 787 migrant farm workers were repatriated to their country of origin for medical reasons. The predominant medical reasons for these repatriations include trauma, musculoskeletal and digestive or gastroenterologic conditions. Neurologic, psychiatric, cancerous and cardiovascular conditions also figured prominently in this study.

By describing the epidemiology of medical repatriation, this study provides an essential instrument to understand and address this complex occupational health phenomenon. Future research and interventions might aim to identify the health outcomes of migrant farm workers following medical repatriation and to enhance data quality and reliability and the validity of how medical repatriations are documented and coded. The medical repatriation of migrant farm workers merits further examination as a global health equity concern. 


\section{References}

1. Labour market opinion statistics - annual statistics 2012, Table 9: Number of temporary foreign worker positions on positive labour market opinions (including accelerated labour market opinions) under the Agricultural Occupations, by location of employment. Ottawa: Employment and Social Development Canada; 2012. Available: http://s3.amazonaws.com/migrants_heroku _production/datas/1215/(LMO)_Statistics__HRSDC_original. pdf? 1384392810 (accessed 2014 Sept. 8).

2. Earle-Richardson G, Jenkins P, Slingerland D, et al. Occupational injury and illness among migrant and seasonal farmworkers in New York State and Pennsylvania,1997-1999: pilot study of a new surveillance method. Am 7 Ind Med 2003;44:37-45.

3. McLaughlin, J, Hennebry, J, Haines, T. Paper versus practice: occupational health and safety protections and realities for temporary foreign agricultural workers in Ontario. Perspectives interdisciplinaires sur le travail et la santé 2014; 16-2. Available: http://pistes.revues.org/3844 (accessed 2014 Sept. 8).

4. Agreement for the employment in Canada of seasonal agricultural workers from Mexico - 2013. Ottawa: Employment and Social Development Canada; 2013. Available: www.esdc.gc.ca/eng/jobs/foreign_workers/agriculture/seasonal /sawpmc2013.pdf (accessed 2014 Sept. 8).

5. McLaughlin, J, Hennebry, J. Pathways to precarity: structural vulnerabilities and lived consequences for migrant farmworkers in Canada. In: Goldring L, Landolt P, editors. Producing and negotiating non-citizenship: precarious legal status in Canada. Toronto: University of Toronto Press; 2013.

6. Hennebry JL, Preibisch K. A model for managed migration? Re-examining best practices in Canada's Seasonal Agricultural Worker Program. International Migration 2012;50:e19-40.

7. Flecker K. Canada's Temporary Foreign Worker Program: model program — or mistake? Ottawa: Canadian Labour Congress; 2011. Available: http://www .canadianlabour.ca/sites/default/files/pdfs/model-program-or-mistake-2011-en .pdf (accessed 2014 Sept. 8)

8. Peart v. Ontario (Community Safety \& Correctional Services), Exhibit 8, Tab 141, file TR-0680-09. Toronto: Human Rights Tribunal of Ontario; 2011.

9. Landis JR, Koch GG. The measurement of observer agreement for categorical data. Biometrics 1977;33:159-74.

10. Hennebry J, Preibisch K, Mclaughlin J, et al. Health across borders - health status, risks and care among transnational migrant farm workers in Ontario. Toronto: CERIS - The Ontario Metropolis Centre; 2012. Available: www .ceris.metropolis.net/wp-content/uploads/2012/03/Health-across-Borders.pdf (accessed 2014 Sept. 8)

11. Hansen E, Donohoe M. Health issues of migrant and seasonal farmworkers. 7 Health Care Poor Underserved 2003;14:153-64.

12. Brower MA, Earle-Richardson GB, May JJ, et al. Occupational injury and treatment patterns of migrant and seasonal farmworkers. 7 Agromedicine $2009 ; 14: 172-8$.
13. Pysklywec M, McLaughlin J, Tew M, et al. Primer: Doctors within borders: meeting the health care needs of migrant farm workers in Canada. CMAJ 2011;183:1039-42.

14. Gustafson CJ, Feldman SR, Quandt SA, et al. The association of skin conditions with housing conditions among North Carolina Latino migrant farm workers. Int 7 Dermatol 2014;53:1091-7.

15. Quandt SA, Jones BT, Talton JW, et al. Heavy metals exposures among Mexican farmworkers in eastern North Carolina. Environ Res 2010;110:83-8.

16. Swanberg JE, Clouser JM, Westneat S. Work organization and occupational health: perspectives from Latinos employed on crop and horse breeding farms. Am 7 Ind Med 2012;55:714-28.

17. Clingerman EM, Brown A. Stress in migrant farmworkers during premigration. Biol Res Nurs 2012;14:27-37.

18. Preibisch K, Hennebry J. Temporary migration, chronic effects: the health of international migrant workers in Canada. CMA7 2011;183:1033-8.

19. McLaughlin J, Hennebry J, Furet A, et al. Migrant worker health project: resource guide for healthcare providers [website]. Waterloo (ON): Migrant Worker Health; 2012. Available: www.migrantworkerhealth.ca/relinks/Booklet .pdf (accessed 2014 Sept. 8).

20. Preibisch K. Foreign workers in Canadian agriculture: not an all-male cast. FOCALPoint 2007;May-June:8-10.

Affiliations: Dalla Lana School of Public Health (Orkin, Lay, Schwandt, Cole), University of Toronto, Toronto, Ont.; Health Studies (McLaughlin), Wilfrid Laurier University, Waterloo, Ont.; Department of Community Health and Epidemiology (Schwandt), College of Medicine, University of Saskatchewan, Saskatoon, Sask.

Contributors: Aaron Orkin and Donald Cole contributed to the study concept and design. Aaron Orkin, Morgan Lay, Michael Schwandt and Donald Cole contributed to data gathering and the design of the data coding system. Morgan Lay completed the primary data analysis. All authors contributed to the analytical interpretation of the data, manuscript preparation and revision; approved the article for publication; and are willing to act as guarantors of the work.

Acknowledgements: Thank you to the physician volunteers who participated in coding the data: Katherine Bingham, Natalie Bocking, Rajesh Girdhari, Ryan Hoskins, Fiona Kouyoumdjian, Barry Pakes and Mei-ling Wiedmeyer. Thank you to Shweta Dhawan for her transcription of the data set and other valuable contributions to the project.

Supplemental information: For the appendix, reviewer comments and the original submission of this manuscript, please see www.cmajopen.ca /content/2/3/E192/suppl/DC1 